\title{
Crosstalk between TLR5 and Notch1 signaling in epithelial cells during intestinal inflammation
}

\author{
MONOWAR AZIZ ${ }^{1,3}$, SHUNJI ISHIHARA ${ }^{1}$, MESBAH UDDIN ANSARY ${ }^{1}$, HIROKI SONOYAMA ${ }^{1}$, \\ YASUMASA TADA $^{1}$, AKIHIKO OKA ${ }^{1}$, RYUSAKU KUSUNOKI ${ }^{1}$, YUJI TAMAGAWA ${ }^{1}$, \\ NOBUHIKO FUKUBA $^{1}$, YOSHIYUKI MISHIMA ${ }^{1}$, TSUYOSHI MISHIRO ${ }^{1}$, NAOKI OSHIMA ${ }^{1}$, \\ ICHIRO MORIYAMA ${ }^{1}$, NORIHISA ISHIMURA ${ }^{1}$, SHUICHI SATO ${ }^{2}$, TAKAFUMI YUKI ${ }^{2}$, \\ KOUSAKU KAWASHIMA ${ }^{1}$ and YOSHIKAZU KINOSHITA ${ }^{1}$
}

\author{
${ }^{1}$ Department of Internal Medicine II, Shimane University School of Medicine, Shimane 693-8051; \\ ${ }^{2}$ Department of Gastrointestinal Endoscopy, Shimane University Hospital, Shimane 690-8504, Japan
}

Received May 17, 2013; Accepted August 27, 2013

DOI: 10.3892/ijmm.2013.1501

\begin{abstract}
During intestinal inflammation, a variety of signaling events are activated to perform several cell functions. Although the distinct roles of these pathways have been elucidated, the effects of their crosstalk activities remain to be clarified. We evaluated the crosstalk between two evolutionary conserved cell signaling systems, toll-like-receptor (TLR) 5 and Notch1, in intestinal epithelial cells during inflammation. Significant induction of the expression of Notch1 and Jagged1 was observed in the distal part of the colon, together with abundant localization of Notch1 intracellular domain (N1ICD) in the surface epithelium of inflamed colonic mucosa. By targeting intestinal epithelial cells, it was shown that recombination-signal-binding-protein-J $\kappa$ (RBP-J $\mathrm{K}$ )-mediated Notch functions are dependent on a flagellin-TLR5-mediated pathway. Conversely, using a $\gamma$-secretase inhibitor, we demonstrated that Notch synergistically increases TLR5-mediated
\end{abstract}

Correspondence to: Dr Shunji Ishihara, Department of Internal Medicine II, Shimane University School of Medicine, 89-1, Enya-cho, Izumo, Shimane 693-8501, Japan

E-mail: si360405@med.shimane-u.ac.jp

Present address: ${ }^{3}$ Center for Immunology and Inflammation, The Feinstein Institute for Medical Research and Department of Surgery, Hofstra North Shore-LIJ School of Medicine, Manhasset, NY 11549, USA

Abbreviations: IBD, inflammatory bowel disease; UC, ulcerative colitis; CD, Crohn's disease; TLR, toll-like-receptor; NF- $\kappa B$, nuclear factor- $\kappa \mathrm{B}$; NEMO, NF- $\kappa \mathrm{B}$ essential modulator; AP-1, activator protein-1; NICD; notch intracellular domain; dll4, delta-like ligand 4; RBP-J $\kappa$, recombination signal binding protein- $\mathrm{J}_{\kappa}$; Jak/ STAT, janus kinase/signal transducer and activator of transcription; TNBS, trinitrobenzene sulfonic acid; DSS, dextran sodium sulfate

Key words: inflammatory bowel disease, TLR5, Notch, Jagged1, $\mathrm{NF}-\kappa \mathrm{B}, \mathrm{NEMO}, \mathrm{IL}-6$
$N F-\kappa B$ activation. In addition, the effects of Notch on the $\mathrm{NF}-\kappa \mathrm{B}$ target gene interleukin-6 (IL-6) expression were revealed by evaluating the $\mathrm{RBP}-\mathrm{J} \kappa$ responsive element in the IL-6 promoter in vitro. Modulation of TLR5 and Notch crosstalk by transient blocking of Notch during the acute phase of colitis was beneficial for ameliorating colonic inflammation as well as disease status. In conclusion, the results suggest the effectiveness of Notch-targeted drug strategy for the treatment of intestinal inflammation.

\section{Introduction}

Aberrant innate-immune response is a characteristic feature of inflammatory bowel disease (IBD), which has two clinical forms, Crohn's disease (CD) and ulcerative colitis (UC) $(1,2)$. The disease progresses due to the uncontrolled activation of a complex group of transcription factors, including nuclear factor- $\kappa \mathrm{B}(\mathrm{NF}-\kappa \mathrm{B})$ and activator protein (AP-1), as well as proinflammatory cytokine genes, such as, tumor necrosis factor- $\alpha$ (TNF- $\alpha$ ), interleukin (IL)-1 $\beta$ and IL-6, which induce inflammation and tissue injury in inflamed sites in the intestine (3). Among several reported cell signaling systems, a mammalian homologue of the Drosophila toll-like receptor (TLR) pathway is known to induce the expression of genes involved in inflammatory responses (4). Previously, we reported the differential expression of TLRs in inflamed intestinal mucosa in a mouse model of colitis and Helicobacter pylori-associated gastritis (5-7). The pivotal roles of TLRs in gut immunity, barrier function and healing during colitis have been noted in various studies $(8,9)$, while the prolonged and uncontrolled immune activation via TLRs, which may aggravate the disease condition, have also been reported (10).

Apart from TLR signaling, other pathways are also vital for the development, regeneration and process of homeostasis, which occur during intestinal inflammation (11-13). The Notch signaling system coordinates a diverse set of cell fate events in metazoans via interactions with transmembrane receptors (Notch1-4) and ligands (Jagged 1, 2 and delta-like ligand $1,3,4)$, followed by proteolytic processing and nuclear translocation of the central signaling molecule, the Notch 
intracellular domain (NICD), which combines with a $\mathrm{CBF} 1 / \mathrm{Su}(\mathrm{H}) / \mathrm{Lag}-1$ (CSL) family transcription factor to induce target gene expression (14). Although previous studies support its developmental role in various tissues and organs $(15,16)$, some of the key influences of the NICD on pathogenesis and cancer progression via the activation of mitogen-activated protein kinases (MAPK), Akt and NF- $\mathrm{KB}$ pathways have also been reported $(17,18)$.

Intestinal epithelium serves as a model of stem cell regeneration and lineage commitment. Multiple Notch receptors and ligands are expressed in the intestines during embryonic development, as well as in adults (19). Canonical Notch signaling in the intestinal crypts maintains stem, progenitor and goblet cell balance during activation of the self-renewal mechanism (20). Studies on Notch during intestinal inflammation have predominantly highlighted its role in tissue regeneration and maintenance of goblet cell balance via a hyper-network with other signaling pathways $(11,21)$. A wide range of Notch crosstalk events with hedgehog ( $\mathrm{Hh})$, bone-morphogenic-protein (BMP), janus kinase/signal transducer and activator of transcription (Jak/STAT) and Wnt have been studied in both normal and pathological conditions in intestinal epithelia (22-24), although less is known about the possible interactions between TLRs and Notch in intestinal tissues during inflammation. Therefore, understanding of the effects of TLR-Notch interactions on innate-immune responses during colitis is considered to be crucial. In the present study, we evaluated the status of Notch in acute colitis and its possible link with the TLR-signaling pathway to generate synergistic effects on the immune system, which may lead to the development of an approach that uses therapeutic targeting for intestinal inflammation.

\section{Materials and methods}

Reagents and antibodies. Trinitrobenzene sulfonic acid (TNBS; Sigma, St. Louis, MO, USA), dextran sodium sulphate (DSS, $5 \mathrm{kDa}$; Wako Pure Chemicals), flagellin (Salmonella typhimurium; InvivoGen, San Diego, CA, USA), recombinant rat Jagged1-Fc (R\&D Systems, Minneapolis, MS, USA), $\gamma$-secretase inhibitor DAPT (Tocris Bioscience, Bristol, UK), NEMO-binding domain (NBD) inhibitory peptide (Imgenex, SanDiego,CA,USA),Lipofectamine2000(Invitrogen,Carlsbad, CA, USA), pNF-кB-Luc (Stratagene, Santa Clara, CA, USA), pRL-TK (Promega, Madison, WI, USA), mock (pZERO-mcs), a mouse dominant-negative TLR5 (pZERO-mTLR5) vector set (InvivoGen), RBP-JK Cignal Reporter assay (SA Biosciences, Valencia, CA, USA), mouse RBP-Jא siRNA (Santa Cruz Biotechnology, Inc., Santa Cruz, CA, USA) were obtained from respective sources. The antibodies used were: anti-cleaved Notch 1 (Val 1744; Cell Signaling Technology), anti-Jagged1 and anti- $\beta$-actin (Santa Cruz).

Experimental colitis and treatment of $\gamma$-secretase inhibitor. Seven-week-old male specific pathogen-free BALB/c mice (Charles River, Japan) were obtained and housed according to our institutional guidelines using a protocol approved by the Ethics Committee of Shimane University, School of Medicine. Initially, a single group of normal mice was used to screen Notch receptors and their ligand expressions in different parts of the gastrointestinal tract tissues using RT-PCR. For a TNBS-induced colitis model, mice were anesthetized for 90-120 min with an intra-peritoneal pentobarbital injection and then given an intrarectal administration of TNBS (100 $\mu 1$, $125 \mathrm{mg} / \mathrm{kg}$ ) dissolved in 50\% ethanol. Control mice received only $50 \%$ ethanol using the same technique. For inhibition of Notch-signaling, mice $(n=5)$ were intraperitoneally injected with the inhibitor of $\gamma$-secretase DAPT (N-3,5-Difluorophe nylacetyl-L-alanyl-2-phenylglycine-1,1-dimethylethyl ester) dissolved in DMSO at a dose of $500 \mathrm{mM} / \mathrm{kg}$ of body weight once at the onset of intrarectal TNBS or 50\% ethanol administration. Mice treated with only DMSO served as the DAPT control group $(n=5)$. Animals were euthanized at 5 days after TNBS administration and disease activity was evaluated using various parameters. For the DSS-induced colitis model, the experimental group was fed $2.5 \%$ DSS dissolved in distilled water for 9 days, while the control group received normal drinking water throughout the experiment. The parameters for colitis evaluation were body weight, colon length and rectal bleeding, which was determined by visual inspection. Mice were weighed each day of the colitis induction period and weight changes were expressed as a percentage of the original weight. After the end of the colitis induction period, the mice were euthanized and the colons resected between the proximal colon and rectum. For histology, colon tissues were fixed with $10 \%$ neutral-buffered formalin and then embedded in paraffin. The sections $(3 \mu \mathrm{m})$ were stained with hematoxylin and eosin (H\&E) and examined under a light microscope by two investigators in a double-blind manner.

In vivo ligation of TLR ligand. For efficient in vivo ligation of the optimal TLR ligand (flagellin) the intra-anal route was selected for their delivery (25). Since under normal conditions the luminal epithelia are arranged in intact apical orientation to be hyporesponsive against commensals, disruption of the epithelia is required prior to in vivo ligation of flagellin. To achieve this, mice were anesthetized for 90-120 min with an intra-peritoneal pentobarbital injection and then given an intrarectal administration of flagellin $(40 \mu \mathrm{g} / \mathrm{kg}$ of mice weight) together with the TNBS $(100 \mu 1,125 \mathrm{mg} / \mathrm{kg})$ dissolved in 50\% ethanol to cause mild injury at the gut lumen. Control mice received only $50 \%$ ethanol using the same technique.

Isolation of mouse colonic epithelial cells. Mouse colonic epithelial cells were isolated as described previously $(25,26)$. Briefly, the distal colonic parts dissected from BALB/c mice were opened and washed three times in Hanks' balanced salt solution (HBSS) (Gibco-BRL, Carlsbad, CA, USA) containing $5 \%$ FBS in a sterile condition. Tissue segments $(5 \mathrm{~mm})$ were incubated with gentle rotation for $15 \mathrm{~min}$ at room temperature in $10 \mathrm{ml}$ of RPMI-1640 containing antibiotics, 5\% FBS and $1 \mathrm{mM}$ DTT (Sigma), followed by washing with HBSS. The tissue segments were incubated for $30 \mathrm{~min}$ at $37^{\circ} \mathrm{C}$ in $10 \mathrm{ml}$ RPMI-1640 complete media and $1 \mathrm{mM}$ EDTA with gentle rotation. Each digested sample was then passed through a nylon mesh to remove mucus and undigested tissue fragments.

Real-time PCR. Total RNA was extracted from colonic tissues and cultured cells using Isogen (Nippon Gene, Toyama, Japan). Equal amounts of RNA were then reverse transcribed 
Table I. Primer sequences.

\begin{tabular}{ll}
\hline Gene (accession no) & \multicolumn{1}{c}{ Sequences (5'-3') } \\
\hline Notch1 & F: GCTGGCTACCATGGGTCTAA \\
(NM_008714) & R: CACAGGTGCCATTGTTGAAG \\
Notch2 & F: TCACAGGGAAGCAGTGTCAG \\
(NM_010928) & R: GGCATCTGTAGGAACCAGGA \\
Notch3 & F: GTCCAGAGGCCAAGAGACTG \\
(NM_008716) & R: ACAGAAGGCCAGCATAA \\
Notch4 & F: CACCTCCTGCCATAACACCT \\
(NM_010929) & R: TGGGTTCATCTCCAGTCCA \\
Dll1 & F: TCCGATACCCAGGTTGTCTC \\
(NM_007865) & R: GGGCTAGGAGCACACTCATC \\
Dl13 & F: GGATGCACTCAACAACCTGA \\
(NM_007866) & R: CCAGGCGATGATAGAGAAGG \\
Dll4 & F: ACCTTTGGCAATGTCTCCAC \\
(NM_019454) & R: TTGGATGATGATTTGGCTGA \\
Jagged1 & F: CCACGTGTTCCACAAACATC \\
(NM_013822) & R: TCACAGTTCTGACCCATCCA \\
Jagged2 & F: AGAATGCAAAGAAGCCGTGT \\
(NM_010588) & R: TGGCTGCCACAGTAGTTCAG \\
Hes1 & F: CTACCCCAGCCAGTGTCAA \\
(NM_008235) & R: CGGTATTTCCCCAACACG \\
$\beta$-actin & F: CGTGAAAAGATGACCCAGATCA \\
(NM_007393) & R: CACAGCCTGGATGGCTACGTA \\
\hline
\end{tabular}

F, forward; R, reverse primer.

into cDNA using a QPCR cDNA kit (Stratagene). A real-time fluorescence PCR assay based on SYBR-Green (Applied Biosystems, Paisley, UK) was then performed using the primers described in Table I.

Western blotting. Western blotting and immunoprecipitation assays from extracted proteins were performed as described previously (27). Briefly, after blocking with $10 \%$ skimmed milk, the membrane was reacted with specific antibodies under optimized conditions and subjected to hybridization with a specific secondary antibody. The primary antibodies were: anti-cleaved Notch 1 (Val 1744; Cell Signaling Technology), anti-Jagged 1 and anti- $\beta$-actin (Santa Cruz). The resulting signals were then visualized using ECL reagent.

Reporter gene assay. For in vitro experiments, cells from the mouse colon cancer cell line Colon-26 (American Type Culture Collection, Middlesex, UK) were grown and plated inn 24-well plates $\left(2.5 \times 10^{4}\right.$ cells/well $)$ in RPMI-1640 with $10 \%$ FBS in a humidified chamber. After 12-16 h, the cells were transfected with an RBP-J $\kappa$ reporter construct with an internal control vector, as described in the manufacturer's instructions. Similarly, co-transfection with mock and DN-TLR5 vectors was also performed using Lipofectamine 2000 in corresponding wells. In order to block the endogenous expression of Jagged1, commercially available mouse Jagged1-specific siRNA was used. For siRNA transfection, Colon-26 cells $\left(2.5 \times 10^{4}\right.$ cells/well) were plated in 24-well culture plates. After 12-16 h, the cells were transfected with 20 pmols each of duplex siRNAs for Jagged1 or non-target-specific negative control, using the siRNA-trasfection reagent. After 18-24 h, the cells had reached $50 \%$ confluence and were transiently transfected with pNF- $\mathrm{B}$-Luc (200 ng/well) and pRL-TK-Renilla-Luc (20 ng/well) using Lipofectamine 2000 (2.5 $\mu \mathrm{l} /$ well). NF- $\kappa \mathrm{B}$ activity was measured using a dual-luciferase reporter assay system (Promega). In another experiment, RBP-Jא reporter constructs combined with a PRL-internal control vector were transfected into Colon-26 cells at 24-36 h according to the manufacturer's instructions, then dual-luciferase assays were performed as described above.

Immunohistochemistry. Frozen colonic tissue samples were sliced into $3-\mu \mathrm{m}$ thick sections and fixed in cold acetone for $20 \mathrm{~min}$. After blocking endogenous peroxidase activity with $0.3 \%$ hydrogen peroxide in methanol, the sections were incubated for $2 \mathrm{~h}$ at room temperature with anti-cleaved Notch1-specific primary $\mathrm{Ab}$ at a dilution of $1 / 100$ and processed with the corresponding protocols using an immunoperoxidase staining kit (Vectastain, Burlingame, CA, USA).

Enzyme-linked immunosorbent assay (ELISA). Interleukin-6 contents in colonic tissues were determined using ELISA (R\&D Systems) according to the manufacturer's instructions. Briefly, total proteins from distal colonic tissues were extracted using lysis buffer (200 mM NaCl, $5 \mathrm{mM}$ EDTA, $10 \mathrm{mM}$ tris, $10 \%$ glycine and $1 \mathrm{mM}$ PMSF, $\mathrm{pH}$ 7.4) and subjected to IL-6 ELISA.

Statistical analysis. Quantitative data are presented as the mean \pm SEM. The Student's t-test or Anova and Student-Newman-Keuls (SNK) test was used for statistical determinations. $\mathrm{P}<0.05$ was considered to indicate statistical significance.

\section{Results}

Notchl and its ligands are activated during intestinal inflammation. In the gastrointestinal tract of normal healthy mice, different Notch receptors and their ligands were shown to be ubiquitously expressed in a tissue-specific manner (Fig. 1A). In our examination of various Notch receptors and their ligand expressions in the present TNBS model of acute colitis, we observed an increased expression of Notch1, delta-like ligand4 (d114) and Jagged1 at the mRNA level in the inflamed distal colons (Fig. 1B). During TNBS-induced colitis, Jagged1 expression was more strongly induced than the other ligands, thus we utilized Jagged1 as a representative Notch ligand in the subsequent experiments. We also evaluated the results of the increased expression of Notch1 and Jagged1 by employing two commonly used chemical models of experimental colitis (TNBS and DSS colitis models), as well as different timelines for disease onset. Interactions between Notch receptors and ligands lead to generation of the functionally active intracellular cleaved part of Notch (NICD). Results of the present study revealed an increased expression of Notch1 and Jagged1 in colonic tissues during the acute phase in the TNBS- and DSS-induced models of colitis, suggesting that a higher level 


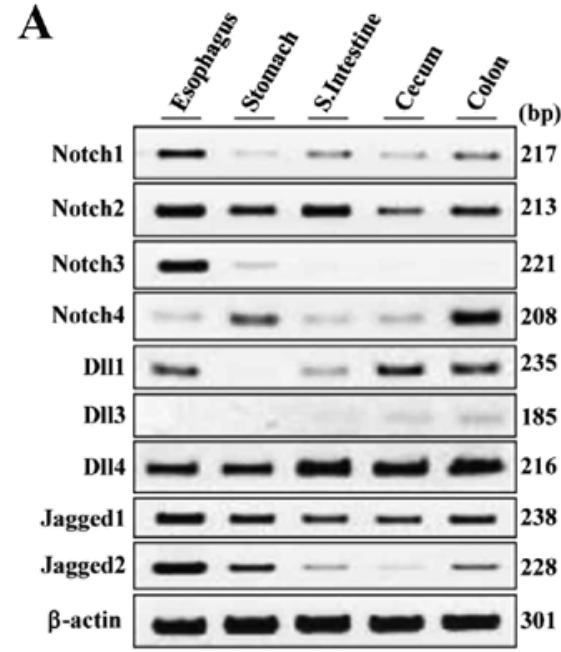

C

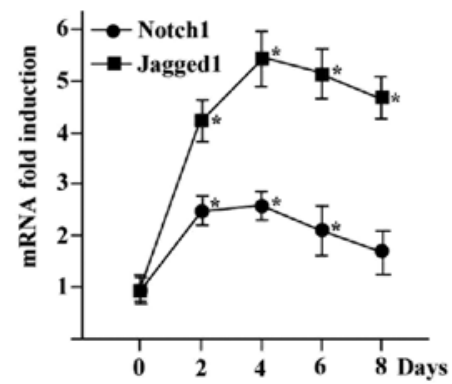

E

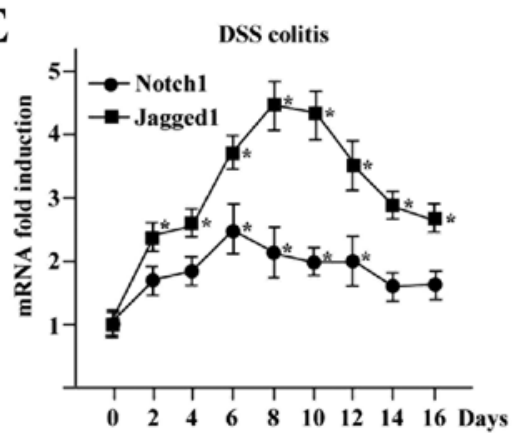

B

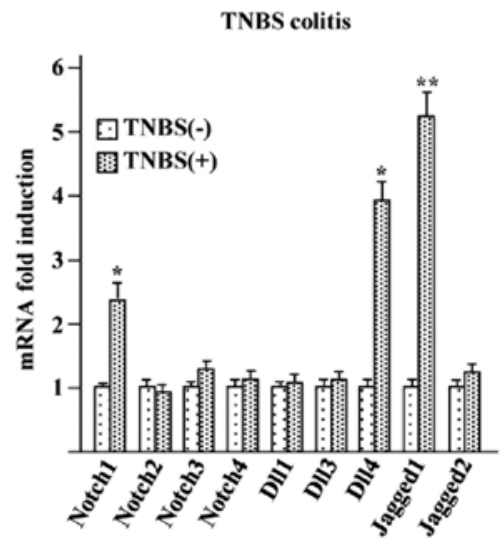

D

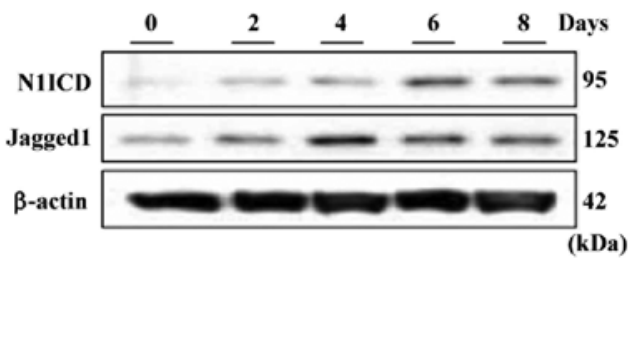

$\mathbf{F}$

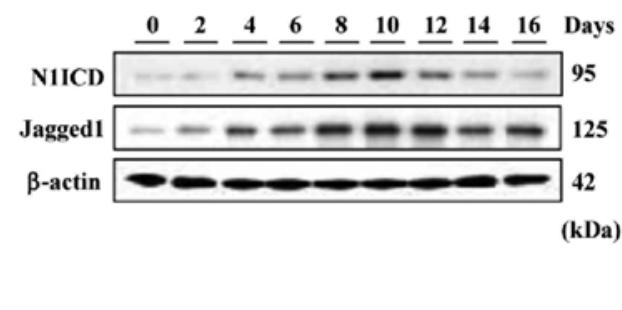

Figure 1. Notch expression during acute colitis. (A) Tissue-specific expression of Notch receptors and ligands in normal mice ( $\mathrm{n}=3$ mice), as revealed by RT-PCR using $50 \mathrm{ng}$ of cDNA as a template with 30 cycles of PCR amplification. (B) Real-time PCR using $50 \mathrm{ng}$ of cDNA prepared from the distal parts of colonic tissues with or without TNBS induction for 5 days. $\beta$-actin served as the internal control. Ratios of mRNA quantity relative to that of TNBS(-) are expressed as fold induction. ${ }^{* *} \mathrm{p}<0.01,{ }^{*} \mathrm{p}<0.05 \mathrm{vs}$. TNBS(-). Error bars indicate the standard error of the mean (SEM) for values obtained from three independent experiments using 5 mice/group. (C-F) Increased expression of Notch1 and Jagged1 at different time-points in mice with acute colitis induced by TNBS $(\mathrm{n}=25)$ and DSS $(\mathrm{n}=27)$, as revealed by real-time PCR and western blotting using anti-N1ICD antibody. $\beta$-actin served as the internal control. ${ }^{*} \mathrm{p}<0.05 \mathrm{vs}$. TNBS(-) or DSS(-). Error bars indicate the SEM for values obtained from three independent experiments.

of cleaved Notch1 (N1ICD) is generated due to the increased expression of Notch1 and Jagged1 (Fig. 1C-F).

NIICD localization during intestinal inflammation. To reveal N1ICD localization, we performed immunohistochemistry examinations of the distal parts of inflamed colons and observed an abundant presence of N1ICD in the TNBS-induced model of acute colitis compared with that of without colitis (Fig. 2A and B). The N1ICD localization was predominantly observed at the surface epithelium (right lane: upper panel; Fig. 2B), as compared to the bottom epithelium and lamina propria infiltrating mononuclear cells (right lane: lower panel; Fig. 2B). As the negative control, the colitic tissue sections were reacted with the $\operatorname{IgG}$ isotypic antibody to exclude any non-specific staining with the N1ICD antibody (Fig. 2C). Epithelial cells are the first cell lineage exposed to bacteria and serve as the first line of defense against pathogens. Therefore, we focused on Notch functions by investigating colonic epithelial cells during inflammation.

TLR5-mediated activation of Notch in intestinal epithelial cells. TLRs are expressed by a large variety of cells and tissues and play an important role in initiating immune responses. Intestinal epithelial cells are responsive to bacterial flagellin and induce proinflammatory gene expression via TLR5 (28). To determine whether TLR5-mediated signaling enhaces 


\section{A TNBS(-), anti-N1ICD Ab}

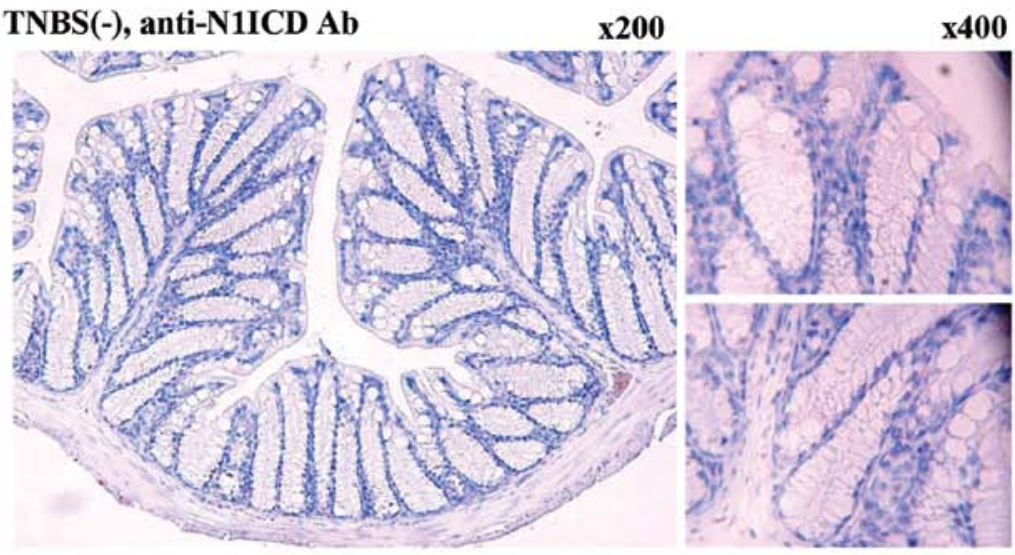

\section{B TNBS(+), anti-N1ICD Ab}

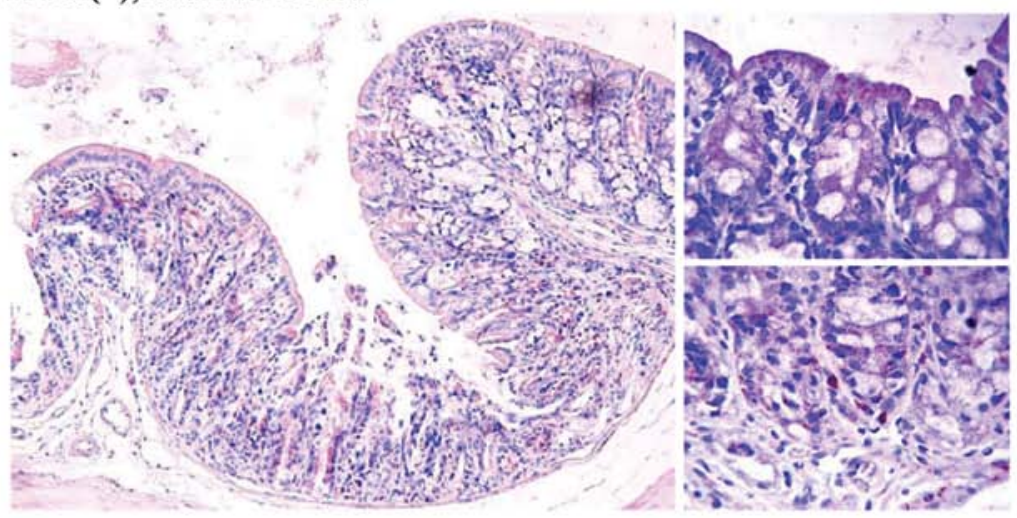

\section{TNBS(+), anti-rabbit IgG Ab}

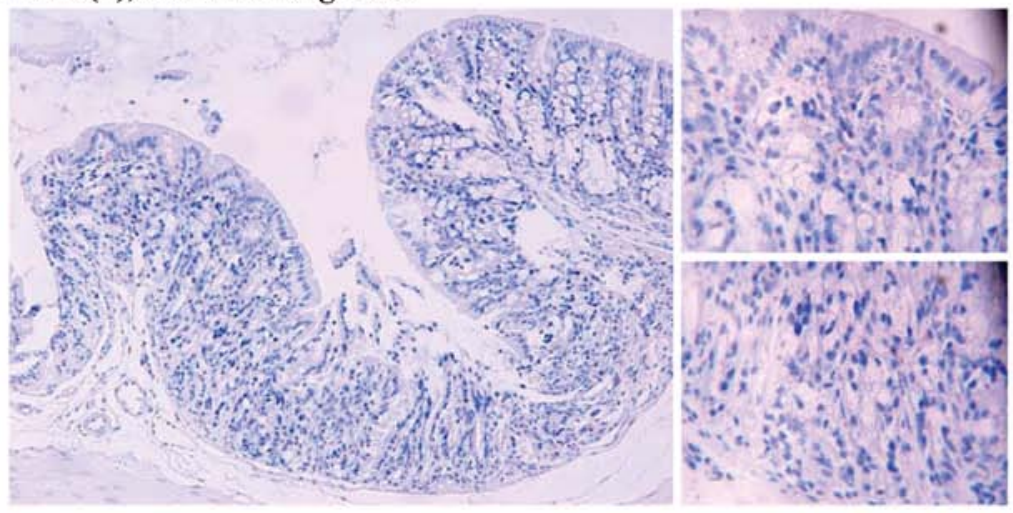

Figure 2. Localization of N1ICD in inflamed colons. Immunohistochemical findings for frozen sections of distal colon tissues reacted with anti-N1ICD antibody (5 mice/group). Colon tissue section of (A) no colitis and (B) TNBS colitis. (C) Frozen sections of distal colon tissues from TNBS colitis (5 mice/group) reacted with anti-rabbit IgG isotype antibody. In each group, surface epithelium and bottom epithelium are presented in the right panels. Representative images (original magnification, x200 and x400) obtained from three independent experiments are shown.

Notch and its ligand expression, we performed in vivo ligation of flagellin to TLR5 and then isolated the colonic epithelial cells to check Notch1 and Jagged1 expression at different time-points. An important point lies with the fact that under normal conditions the colonic mucosa remains intact and thus becomes hyporesponsive to commensals. Therefore, the TLR ligands were administered together with the TNBS dissolved in $50 \%$ ethanol into the rectum of the mice in order for the gut epithelial barrier to become disrupted in order to efficiently recognize the TLR-ligands. As noted in Fig. 3A, a limited dose of intrarectal flagellin injection induces the Notch1 and Jagged1 expression in a time-dependent manner. On the other hand, the in vivo LPS effects on colonic epithelial cells for the induction of Notch1 and Jagged1 were not so marked as that of in vivo flagellin stimulation (Fig. 3B), which may be due to the fact that the colonic epithelial cells were less responsive to LPS. In addition, we confirmed Notch signaling in the cell line (Colon-26) by evaluating the Notch target gene, Hairy and enhancer of split 1 (Hes1) expression under recombinant Jagged1-Fc or flagellin-treated conditions. As is evident in 
A

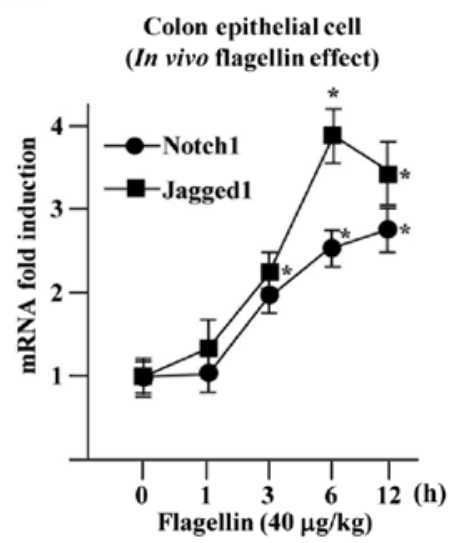

C

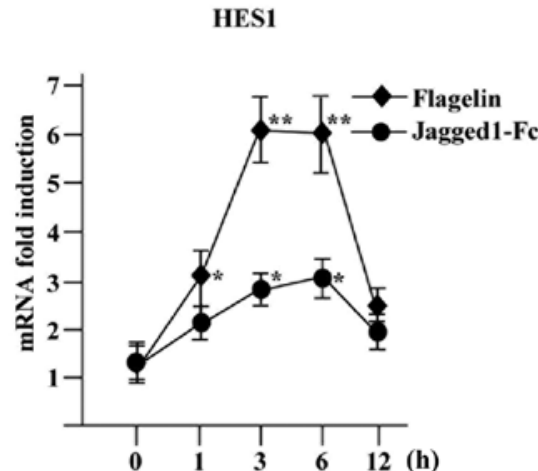

$\mathbf{E}$

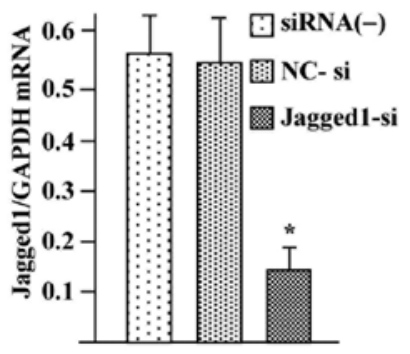

B

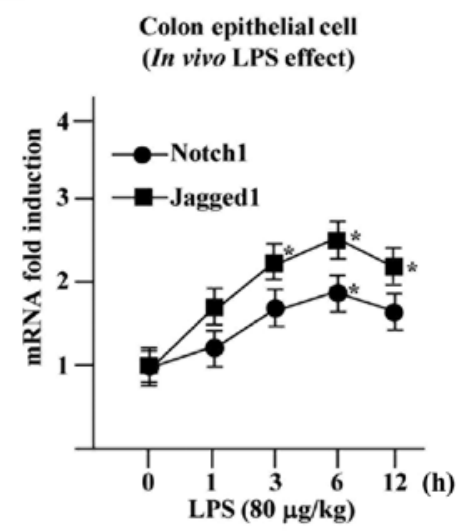

D

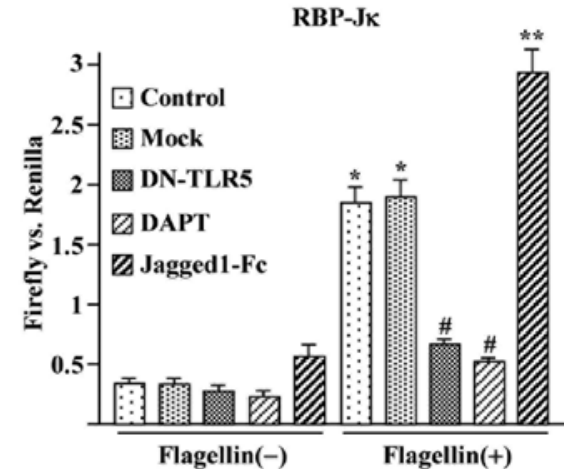

F

RBP-JK

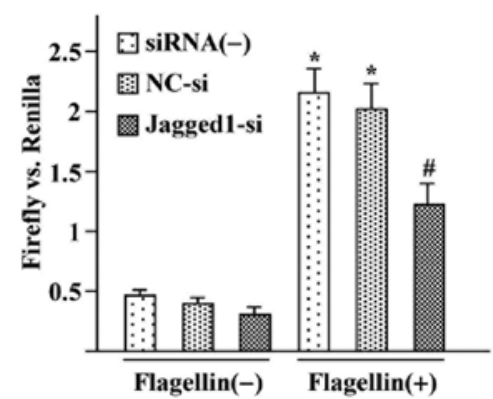

Figure 3. Flagellin-induced expression of Notch in colon epithelial cells. (A and B) Mice were anesthetized for 90-120 min with an intra-peritoneal pentobarbital injection and then given an intrarectal administration of TNBS $(100 \mu 1,125 \mathrm{mg} / \mathrm{kg})$ dissolved in $50 \%$ ethanol, with or without flagellin $(40 \mu \mathrm{g} / \mathrm{kg})$ or LPS $(80 \mu \mathrm{g} / \mathrm{kg})$. Colonic epithelial cells were then harvested for Notch1 and Jagged1 expression from the extracted total RNA by real-time PCR at different time-points. $\beta$-actin served as the internal control intrarectal flagellin injection induces the Notch1 and Jagged1 expression in a time-dependent manner. " $\mathrm{p}<0.05$ vs. Flagellin (-) or LPS (-). Error bars indicate the SEM for values obtained from three independent experiments. (C) Colon- 26 cells ( $1 \times 10^{5}$ cells) were cultured in 6-well plates in the presence or absence of flagellin at various time points, and Hes1 expression was assessed using real-time PCR. Flagellin significantly induced the Hes1 expression in Colon- 26 cells. "p $<0.05$ vs. Flagellin(-)/Jagged1-Fc(-), respectively. Error bars indicate the SEM for values obtained from three independent experiments. (D) Effects of flagellin on RBP-Jא-mediated reporter gene expression. Colon- 26 cells $\left(2.5 \times 10^{4}\right.$ cells/well) were plated in 24-well plates. After 12-16 h, the cells were transfected with an RBP-JK reporter construct with an internal control vector, as described in the manufacturer's instructions. Similarly, co-transfection with mock and DN-TLR5 vectors was also performed using Lipofectamine 2000 in corresponding wells. At $12 \mathrm{~h}$ after transfection, the cells were treated with DAPT $(10 \mu \mathrm{M})$, Jagged1-Fc $(5 \mu \mathrm{g} / \mathrm{ml})$ and flagellin $(10 \mathrm{ng} / \mathrm{ml})$ for $12 \mathrm{~h}$. A dual luciferase assay was then performed using total cell extracts. A significant induction of N1ICD-RBP-Jk-mediated reporter gene expression following flagellin stimulation was observed. RBP-JK activity was increased in the presence of Notch ligand Jagged1, whereas it was reduced in the presence of DAPT. ${ }^{* *}$ p $<0.01,{ }^{*}$ p $<0.05$ vs. Flagellin(-) Control; ${ }^{\#} \mathrm{p}<0.05$ vs. Flagellin(+) Control. Error bars indicate the SEM for values obtained from three independent experiments. (E) In order to block the endogenous expression of Jagged1, commercially available mouse Jagged1-specific siRNA was used. For siRNA transfection, Colon-26 cells $\left(2.5 \times 10^{4}\right.$ cells/well) were plated in 24-well culture plates. After 12-16 h, the cells were transfected with 20 pmols each of duplex siRNAs for Jaggedl or non-target-specific negative control, using the siRNA-trasfection reagent. To determine inhibition of the target gene, the Jagged1 expression was assessed by real-time PCR at $\sim 24-36 \mathrm{~h}$ after transfection. " $\mathrm{p}<0.05$ vs. negative control siRNA. Error bars indicate the SEM for values obtained from three independent experiments. (F) Effects of Jagged 1 siRNA on flagellin-induced RBP-JK reporter gene expression. Colon-26 cells $\left(2.5 \times 10^{4}\right.$ cells/well $)$ were plated in 24 -well plates. After $12-16 \mathrm{~h}$, the cells were co-transfected with 20 pmols each of duplex siRNAs for Jagged1 or negative control and RBP-JK reporter constructs with internal control using trasfection reagent, as described in the manufacturer's instructions. At $24-36 \mathrm{~h}$ after transfection, the cells were treated with flagellin $(100 \mathrm{ng} / \mathrm{ml})$ for $12 \mathrm{~h}$, after which

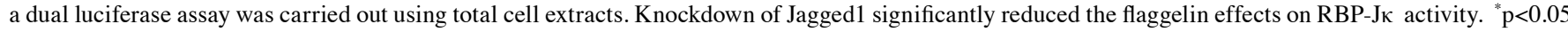
vs. Flagellin(-) siRNA(-)/NC-si; ${ }^{*} \mathrm{p}<0.05$ vs. Flagellin(+) siRNA(-)/NC-si. Error bars indicate the SEM for values obtained from three independent experiments. 
Fig. 3C, flagellin significantly induced the Hes1 expression in Colon-26 cells in a time-course change manner, while these effects were comparatively lower in the presence of only recombinant Jagged1-Fc treatment, supporting the possible involvement of TLR signaling in the induction of Notch target genes in colonic epithelial cells.

Notch1 function is mediated via the nuclear translocation of N1ICD, which is then combined with RBP-JK and recruits several co-activators, leading to target gene activation. To determine the effect of flagellin for inducing N1ICD-RBP-Jк via a TLR5-mediated pathway, we utilized a dominant-negative TLR5 (DN-TLR5) expression vector lacking the intracellular TIR-domain, which recognized its ligand, but was unable to induce the signaling cascade. We then proceeded to the experiment utilizing the DN-TLR5 vector and observed a significant induction of N1ICD-RBP-Jk-mediated reporter gene expression following flagellin stimulation, which was significantly reduced by DN-TLR5, but not mock vector transfection (Fig. 3D). Moreover, we observed that RBP-JK activity was significantly increased in the presence of the Notch ligand Jagged1, whereas it was reduced in the presence of the commercially available $\gamma$-secretase inhibitor (DAPT) which protects receptor-ligand-mediated proteolytic cleavage to produce NICD by the $\gamma$-secretase enzyme, even though flagellin and Jagged1 were present (Fig. 3D). Alternatively, to evaluate the role of Jagged1 in Notch signaling we treated Colon-26 cells with Jagged1-specific siRNA and after evaluating the siRNA efficiency by its ability to knock down the target gene expression $>75 \%$ as compared to the negative control siRNA (Fig. 3E), we conducted additional studies to evaluate the effects of Jagged1 knockdown on Notch signaling as revealed

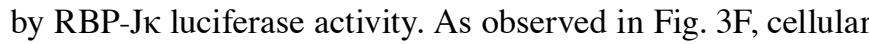
knockdown of Jagged1 significantly reduced the flagellin effects on RBP-JK reporter activity, suggesting the crucial role of Jagged1 on flagellin-induced Notch signaling. Collectively, these findings strongly suggest that TLR5-mediated Notch1 and Jagged1 activation leads to increased functional activity for N1ICD-RBP-JK-mediated gene expression in intestinal epithelial cells.

TLR5 and Notch crosstalk in intestinal epithelial cells: Role of $N F-\kappa B$ and NEMO. After confirming the features of TLR5-mediated activation of Notch1 signaling, we investigated its role in the TLR5 canonical pathway for activation of $\mathrm{NF}-\kappa \mathrm{B}$ in colon epithelial cells. In this examination, we aimed to block Notch signaling using DAPT and perform several in vitro and in vivo experiments. We observed that colonic epithelial cells treated with DAPT had significantly reduced levels of flagellin-induced NF- $\mathrm{B}$ activation, whereas the addition of exogenous recombinant Jagged1 protein increased $N F-\kappa B$ activity to a level greater than that of the flagellin-treated conditions (Fig. 4A). The NF- $\kappa$ B essential modulator (NEMO) seems to be a pivotal regulator of $N F-\kappa B$ signaling pathways, which facilitates subsequent phosphorylation and activation of IKK $\alpha$ or IKK $\beta$ through interaction with the NEMO-binding domain (NBD) and promotes downstream $\mathrm{I} \kappa \mathrm{B}$ ubiquitinoylation, phosphorylation and degradation for $\mathrm{NF}-\kappa \mathrm{B}-$ mediated gene transcription $(29,30)$. In cells, NEMO expression is closely regulated, as cells lacking NEMO fail to activate $\mathrm{NF}-\kappa \mathrm{B}$ in response to a wide range of stimuli (31), while its induced expression leads to the altered expression of NF- $\kappa$ B and AP-1 (32). Since NBD is essential for NEMO functions, we investigated NEMO involvement in flagellinand N1ICD-RBP-Jא-mediated NF- $\kappa \mathrm{B}$ activation. For this experiment, we treated cells with NBD inhibitor peptide, which serves as an IKK $\alpha / \mathrm{IKK} \beta$ decoy and prevents formation of the IKK complex and observed that NF- $\kappa \mathrm{B}$ activity was unchanged with various stimuli (flagellin, DAPT, recombinant Jagged1-Fc) (Fig. 4A). These results suggest that Notch and TLR5 crosstalk activities in colon epithelial cells during inflammation increases NF- $\kappa \mathrm{B}$ activity via NEMO.

Interleukin-6 activation: Role of TLR5- and Notch1-RBP-Jkmediated pathways. We examined the role of TLR5- and Notch1-RBP-Jk-mediated pathways in colonic epithelial cells, associated with the expression of pro-inflammatory cytokines. Colon-26 cells treated with flagellin showed an increased production of IL- 6 , as compared to TNF- $\alpha$ and IL- $1 \beta$ cytokines (Fig. 4B). Thus, we focused on IL-6 and performed several experiments using the $\gamma$-secretase inhibitor DAPT, Notch ligand Jagged1-Fc and TLR5 ligand flagellin to determine whether TLR5 and Notch collectively influence IL-6 production. As shown in Fig. 5B, IL-6 promoter activity following flagellin stimulation was reduced in the presence of DAPT, whereas it was significantly induced following treatment with exogenous recombinant Jagged1 protein (Fig. 4C). An analysis of the IL-6 promoter conducted by Vales et al (33) revealed the presence of an RBP-Jk consensus site at the proximal end for optimum activation of the target gene. To further investigate whether flagellin-induced IL-6 production is affected in RBP-JK knockdown cells, we transfected Colon-26 cells with commercially available mouse RBP-JK-specific siRNA and after evaluating the siRNA efficiency by its ability to knock down the target gene expression over that of the negative control siRNA (Fig. 4D), we carried out studies to evaluate the effects of RBP-JK knockdown on flagellin-induced IL-6 production as revealed by real-time PCR. According to the results, we observed that the time-course changes of IL-6 expression by flagellin become significantly reduced in RBP-Jא siRNA-transfected cells (Fig. 4E). Collectively, these findings clearly demonstrate the cumulative effects of TLR5 and N1ICD-RBP-J $\kappa$ for flagellin-dependent IL-6 induction in colonic epithelial cells.

In vivo treatment with $\gamma$-secretase inhibitor ameliorates intestinal inflammation in acute colitis. Based on our in vitro findings, Notch signaling was blocked in a transient manner by intraperitoneal injection of the $\gamma$-secretase inhibitor DAPT during the onset of acute colitis in mice, and IL-6 production and colitis parameters in inflamed colonic tissues were assessed. First, we evaluated in vivo DAPT efficacy by checking N1ICD status in colonic tissues and confirmed that treatment with DAPT reduced N1ICD contents in the TNBS-treated mice groups (Fig. 5A). Our results also showed the decreased production of IL- 6 in colon tissues from TNBS-treated mice treated with DAPT as compared to those treated with DMSO (Fig. 5B), suggesting that the decreased colonic IL-6 production may be due to the inhibition of Notch signaling. Since decreases in $\mathrm{NF}-\kappa \mathrm{B}$ and proinflammatory cytokines ameliorate experimental colitis $(34,35)$, we also 
A

NF-KB

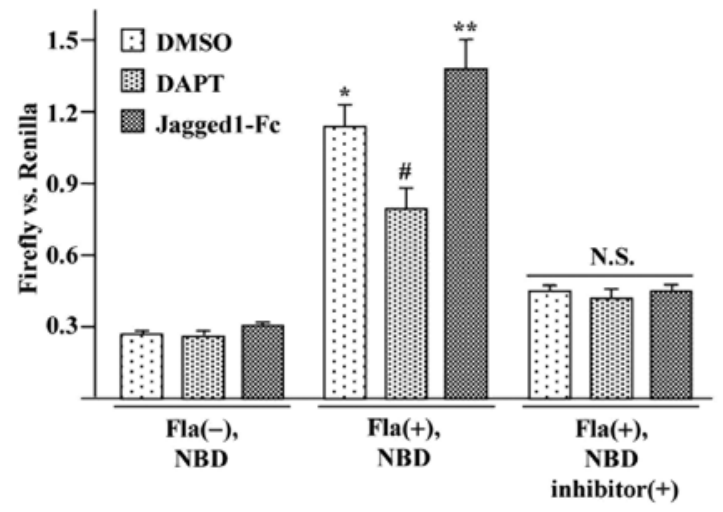

B

C

pIL-6/1278-Lue
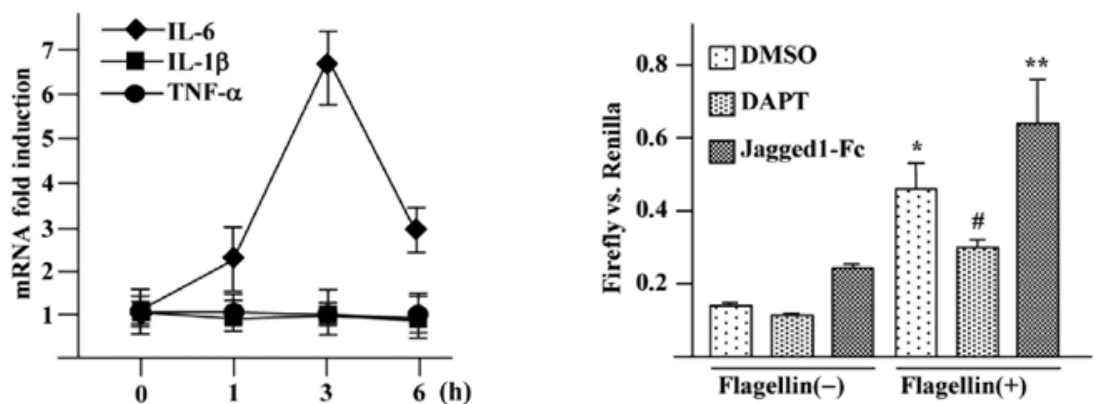

D

$\mathbf{E}$

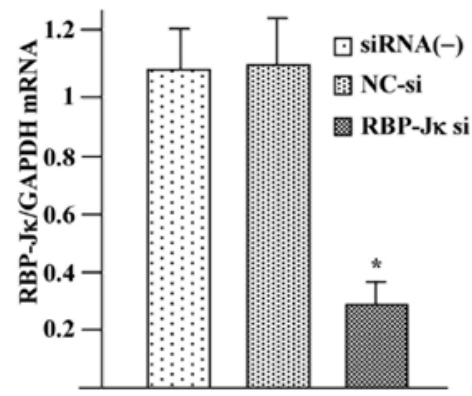

IL-6

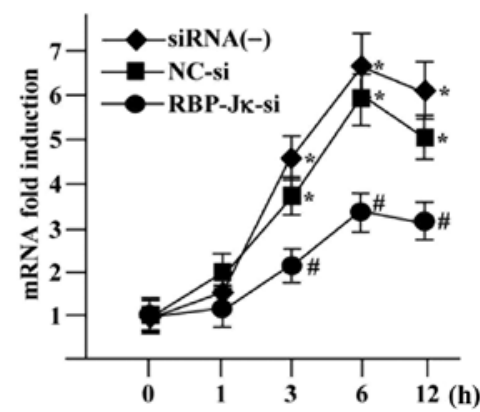

Figure 4. (A) In vitro effects of Notch on TLR5-mediated NF- $\mathrm{BB}$ signaling with or without treatment of NEMO-binding domain (NBD) inhibitor peptide. Colon-26 cells $\left(2.5 \times 10^{4}\right.$ cells/well) were plated in 24 -well plates for $12-16 \mathrm{~h}$, then transfected with pNF-kB-luc and pRL-TK-luc vectors using Lipofectamine 2000. At $12 \mathrm{~h}$ after transfection, the cells were treated with or without NBD inhibitor peptide $(100 \mu \mathrm{M})$, DAPT $(10 \mu \mathrm{M})$, recombinant Jagged1 $(5 \mu \mathrm{g} / \mathrm{ml})$ and flagellin $(100 \mathrm{ng} / \mathrm{ml})$. N.S., not statistically significant. ${ }^{* *} \mathrm{p}<0.01,{ }^{*} \mathrm{p}<0.05$ vs. Flagellin(-) DMSO; ${ }^{*} \mathrm{p}<0.05$ vs. Flagellin(+) DMSO. Error bars indicate the SEM for values obtained from three independent experiments. (B-E) In vitro effects of Notch on TLR5-mediated IL-6 activation. (B) Colon-26 cells $\left(2.5 \times 10^{4}\right.$ cells $/$ well $)$ were plated in 24 -well culture plates in the presence or absence of flagellin $(10 \mathrm{ng} / \mathrm{ml})$ at various time-points. IL-6, IL- $1 \beta$ and TNF- $\alpha$ expression was assessed by real-time PCR from the extracted RNA samples at different time-points. Error bars indicate the SEM for values obtained from three independent experiments. (C) Mouse IL-6 promoter construct, pIL-6/1278-luc (200 ng/well) and pRL-TK-luc (20 ng/well) were transfected using Lipofectamine 2000 ( $2.5 \mu \mathrm{l} /$ well) into Colon-26 cells $\left(2.5 \times 10^{4}\right.$ cells/well), plated in 24 -well cell culture plates. Following treatment for $12 \mathrm{~h}$ with or without DMSO, DAPT $(10 \mu \mathrm{M})$, Jagged1-Fc $(5 \mu \mathrm{g} / \mathrm{ml})$ and flagellin $(10 \mathrm{ng} / \mathrm{ml})$ for $12 \mathrm{~h}$, dual luciferase assays were performed with extracted proteins. ${ }^{* *} \mathrm{p}<0.01$, "p $<0.05$ vs. Flagellin(-) DMSO; $\# \mathrm{p}<0.05$ vs. Flagellin(+) DMSO. Error bars indicate the SEM for values obtained from three independent experiments.

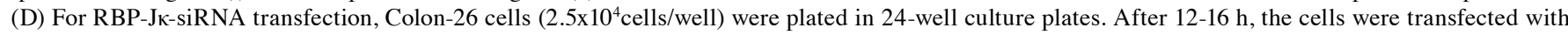
20 pmols each of duplex siRNAs for RBP-Jк- or non-target-specific negative control, using the siRNA-trasfection reagent. Inhibition of RBP-JK expression was assessed by real-time PCR at $\sim 24-36 \mathrm{~h}$ after transfection. " $\mathrm{p}<0.05$ vs. negative control siRNA. Error bars indicate the SEM for values obtained from three independent experiments. (E) At 24-36 h after siRNA tansfection, Colon-26 cells were stimulated with flagellin (10 ng/ml) and the IL-6 expression was assessed at different time-points. " $\mathrm{p}<0.05$ vs. Flagellin(-) siRNA(-)/NC-si; ${ }^{*} \mathrm{p}<0.05$ vs. Flagellin(+) siRNA(-)/NC-si. Error bars indicate the SEM for values obtained from three independent experiments.

evaluated colitis parameters in TNBS mice with or without DAPT treatment. Our findings showed improved disease features in mice with colitis caused by intraperitoneal DAPT, as evaluated by body weight change, colon length and histo- logical results (Fig. 5C-E). In addition, the total colitis scores shown in Fig. 5F suggest that the transient blocking of Notch signaling by DAPT is effective for ameliorating experimental colitis in mice. 
A

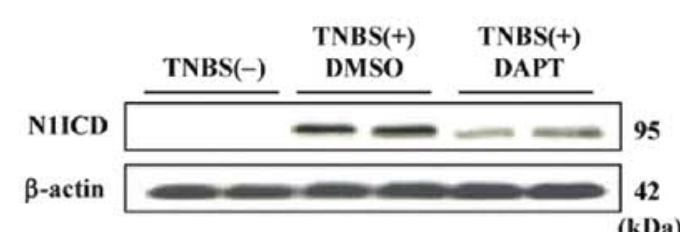

B

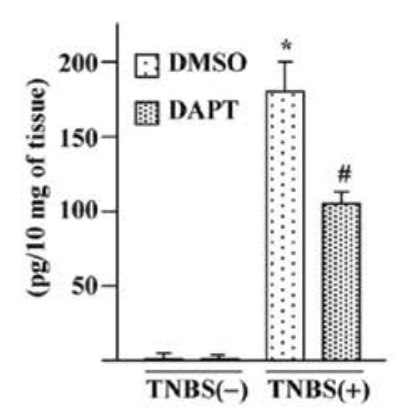

C

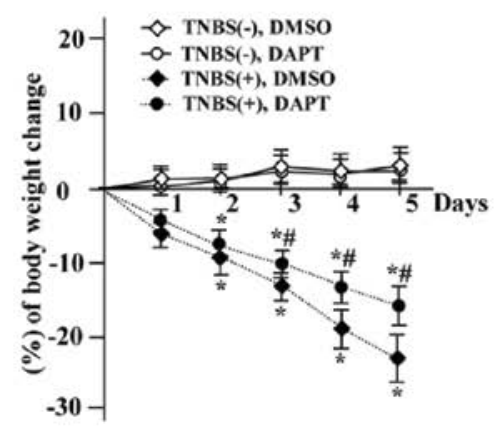

D

$$
\mathbf{E}
$$

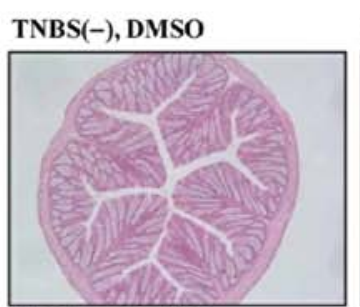

TNBS(+), DMSO

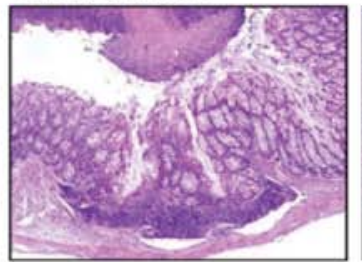

TNBS(-), DAPT

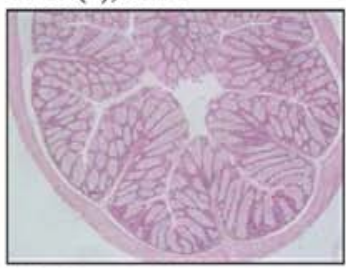

TNBS(+), DAPT

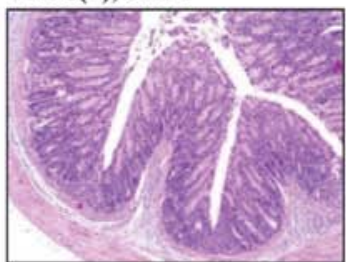

$\mathbf{F}$

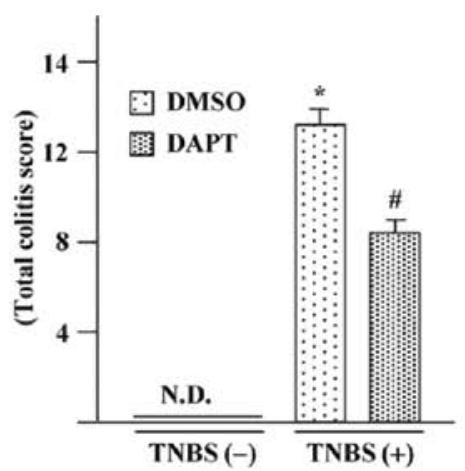

Figure 5. In vivo effects of DAPT during TNBS-mediated acute colitis. (A) DAPT was intraperitoneally injected into mice (5 mice/group) at the time of intrarectal TNBS administration. Five days after TNBS treatment, the distal colonic part was dissected from mice treated with or without DAPT or TNBS, then N1ICD status was checked by western blotting using anti-N1ICD antibody. $\beta$-actin served as the loading control. The image shown is representative of results obtained from three independent experiments. (B) IL-6 contents in dissected colon tissues treated with or without DAPT or TNBS were assessed by ELISA. (C) Effects of DAPT on body weight changes in TNBS-treated mice. Data are expressed as serial changes in percentage of weight change until euthanasia. "p $<0.05$ vs. TNBS(-) DMSO; " $\mathrm{p}<0.05$ vs. TNBS(+) DMSO. Error bars indicate the SEM for values from three independent experiments (5 mice/group). (D) Representative figure of in vivo effects of DAPT on colon length in mice with TNBS-induced colitis. (E) Representative image of histological changes in distal colonic lesions in mice with TNBS-induced colitis with or without DAPT (original magnification, x20). (F) Colonic histological scores. During each histological examination, three different parameters were determined: severity of inflammation (based on polymorphonuclear neutrophil infiltration; 0-3: none, slight, moderate, severe), depth of injury (0-3: none, mucosal, mucosal and submucosal, transmural) and crypt damage (0-4: none, basal one-third damaged, basal two-thirds damaged, only surface epithelium intact, entire crypt and epithelium lost). The score for each parameter was multiplied by a factor reflecting the percentage of tissue involvement $(\mathrm{x} 1,0-25 \% ; \mathrm{x} 2,26-50 \% ; \mathrm{x} 3,51-75 \% ; \mathrm{x} 4,76-100 \%)$ and all values were added to a sum, with a maximum possible score of 40. N.D., not detected. " $\mathrm{p}<0.05$ vs. TNBS(-) DMSO; ${ }^{\#} \mathrm{p}<0.05$ vs. TNBS(+) DMSO.

\section{Discussion}

In normal body systems, Notch receptors and their ligands participate in several cell fate decisions in different tissues and organs, while their dysfunction leads to an abnormal pathophysiology (40). With that background in mind, we conducted the present investigation, which revealed a signifi- cant induction of the Notch1 receptor and its ligands during the acute phase of experimental colitis in mice. Although Notch signaling components are expressed in an aberrant manner during systemic and intestinal inflammation, the mechanism of this alteration is largely unclear $(11,36,37)$. Gut epithelial cells perform barrier functions against pathogenic agents present in the lumen. During colitis, the disrupted gut 

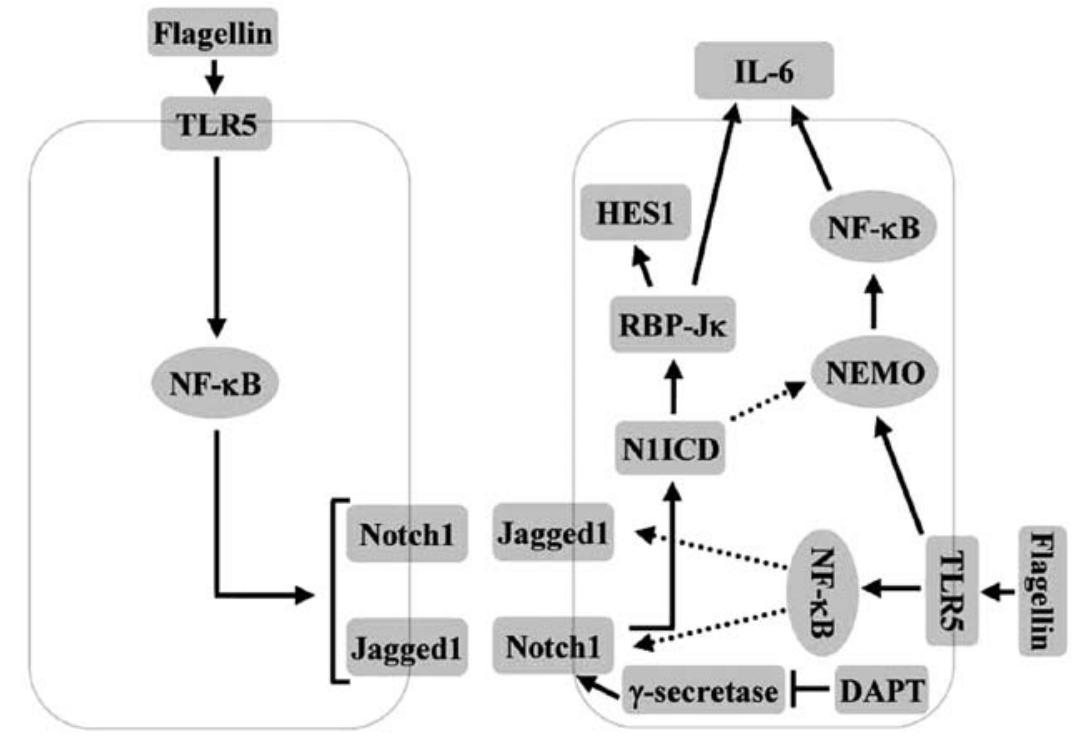

Figure 6. Crosstalk between TLR5 and Notch1 signaling in adjacent epithelial cells during intestinal inflammation. Flagellin-induced TLR5 signaling leads to an increased expression of Notch1 and Jagged1, which facilitates receptor-ligand-induced cleavage of N1ICD by $\gamma$-secretase for RBP-Jк-mediated IL-6, as well as the canonical Notch target gene, Hes1 expression. Using DAPT, a $\gamma$-secretase inhibitor, we found evidence that TLR5 and Notch1 cumulative signaling exhibit control over target gene (IL-6) expression in colonic epithelial cells. DAPT not only inhibited RBP-JK functions by blocking production of N1ICD, but also reduced TLR5 canonical signaling by modulating NEMO. Since DAPT inhibits N1ICD generation, we speculated that the effects of N1ICD-mediated

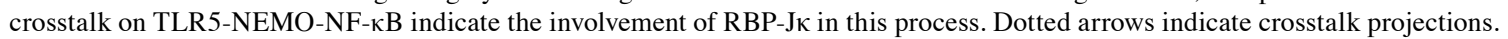

barrier permits luminal flora to invade and induce immune responses via TLR pathways in an uncontrolled manner. Our present findings revealed that TLR5 mediates the induction of N1ICD, the functional part of Notch1, as well as its ligand Jagged1 in colonic epithelial cells. Furthermore, we confirmed the presence of TLR5 and Notch crosstalk activity during colonic inflammation, a combination that profoundly influences NF- $\kappa \mathrm{B}$ activity through NEMO and IкB located downstream (Fig. 6). Moreover, our findings demonstrate that Notch signaling increases pro-inflammatory cytokine IL- 6 production through an NF- $\kappa B-$ and RBP-J $\kappa$-mediated pathway in colon epithelial cells and also showed that transient blockage of Notch signaling reduces intestinal inflammation during experimental colitis.

The focus on colon epithelial cells followed histological findings of inflamed colon specimens, in which N1ICD staining was predominantly localized in the surface epithelia, with some staining also observed in the basal epithelial layer and lamina propria mononuclear cells (Fig. 2). A recent study found an abundance of crypt N1ICD, which was considered to help maintain the commitment of the fine-tuned progenitor lineage to absorptive and secretory fates in injured epithelium during the regeneration phase of experimental colitis (11). Our contrasting results may have been due to the fact that we investigated the acute stage of colitis, while the mentioned study focused on the healing phase. Notch is an evolutionary conserved network that orchestrates several cell fates like a multiple edged sword $(14,15)$, thus discrepancies of Notch functions at different stages of body events may be usual phenomena. Under normal conditions, the gut maintains epithelial turnover via crosstalk between epithelial and underlying mesenchymal cells in the intestinal stem cell niche. This crosstalk is mediated by a complex pathway that includes Notch, Wnt, Hedgehog, PI3K and BMP. The gene expression patterns of human colon top and basal crypts are distinct and the Notch and Wnt pathway components are mainly localized in the proliferative compartment, rather than the area of differentiation $(20,21,38)$. This complex Notch network functions to maintain intestinal homeostasis and has been previously described $(20,37)$. The present results, however, show a different role for Notch in intestinal inflammation during acute colitis.

Since we observed Notch signaling activation during the acute phase of colitis, we determined how this activation was initiated. Among a variety of signals that occur in colitis, TLR family members perform distinct roles in the innate and adaptive immune systems (3). As for TLR and Notch interactions, a relatively small number of studies involving only macrophages have been performed $(17,39)$, while no studies have been conducted with regard to epithelial cells with or without disease. Therefore, we evaluated Notch activation, which was dependent on flagellin (a potent inducer of TLR5) in intestinal epithelial cells to clarify the manner in which Notch is activated during the acute phase of intestinal inflammation. Events downstream of TLR-mediated signaling often result in activation of the NF- $\mathrm{BB}$ pathway. Therefore, apart from the Notch canonical pathway (14), we speculated that Notch mediates all interactions with TLR-activated downstream products. Recently, Notch-mediated NF- $\kappa B$ and Akt activation following stimulation with TLR ligands was reported in macrophages (17). Bedogni et al also showed a functional relationship between Notch1 and the PI3K/Akt/NF- $\kappa B$ pathway in melanoma development (18). Furthermore, the overall regulation of NF- $\kappa \mathrm{B}$ by different Notch family members has been clearly demonstrated in previous studies and reviews $(40,41)$, which mainly showed the direct effects of Notch towards NF- $\kappa \mathrm{B}$, rather than describing any interactions with the various TLR pathways. In studies of how Notch regulates NF- $\kappa B$, it has been reported that Notch mediated 
the transcriptional activation of p50, p65, RelB and c-Rel $\mathrm{NF}-\kappa \mathrm{B}$ subunits in bone marrow hematopoietic precursors (42), or facilitated their nuclear retention (40). Based on those findings, we assessed two key points of NF- $\mathrm{B}$ activation, $\mathrm{I} \kappa \mathrm{B}$ and the upstream regulator of IKKs, the NEMO status. We found that Notch1 signaling maintains TLR5-mediated $\mathrm{NF}-\kappa \mathrm{B}$ activity by increasing I $\mathrm{B}$ degradation and NEMO ubiquitinoylation, while blocking the Notch pathway which is capable of reducing these functions. After showing that Notch1 influences TLR5-mediated NF- $\kappa \mathrm{B}$ activation in intestinal epithelial cells, we determined its functional role by assessing IL-6, an epithelium-specific pro-inflammatory cytokine regulated by $\mathrm{NF}-\kappa \mathrm{B}$, during experimental colitis (3). Similar to a previous study, which showed that Notch signaling directly regulates cytokine production in lymphocytes (43), we observed comparable results with IL-6 and colon epithelial cells in several in vitro and in vivo findings.

The fine-tuned TLR apparatus has an ambiguous response towards the GI immune system, with both beneficial and harmful outcomes possible for the host (9). However, compelling evidence suggests that TLRs have several potent functions in inflammatory bowel diseases. In a healthy host, TLRs may drive distinct immune mechanisms necessary for protecting barrier integrity and eliminating invading microorganisms, thus efficiently maintaining tolerance and homeostatic balance of the intestinal mucosa. By contrast, TLRs may induce potentially inappropriate or overactive signaling pathways in a susceptible host, thus leading to amplification and perpetuation of aggressive immune responses that contribute to detrimental tissue injury and, consequently, chronic inflammation (45). Our experiments with the $\gamma$-secretase inhibitor DAPT clearly revealed the inhibition of IL- 6 production by modulating $\mathrm{NF}-\kappa \mathrm{B}$ and RBP-J $\kappa$ in flagellin-treated colon epithelial cells as well as experimental colitis. Consistent with our findings, other reports have also noted strong therapeutic potential by blocking Notch, Wnt and Hh in intestinal inflammation (36). Nevertheless, controversy remains, as although blocking Notch reduces inflammation, in certain cases it may delay healing. These ambiguities may be due to prolonged treatment with the Notch inhibitor or administration during the healing phase of the disease. We performed transient blocking of Notch signaling using a single dose during the onset of acute colitis, which overcame that limitation and provided a wealth of evidence showing that the $\gamma$-secretase inhibitor ameliorates inflammation, thus suggesting the effectiveness of a Notch-targeted drug strategy for treatment of intestinal inflammation.

\section{References}

1. Ishihara S, Aziz MM, Yuki T, Kazumori H and Kinoshita Y: Inflammatory bowel disease: review from the aspect of genetics. J Gastroenterol 44: 1097-1108, 2009.

2. Mizoguchi A and Mizoguchi E: Inflammatory bowel disease: past, present, and future: lessons from animal models. J Gastroenterol 43: 1-17, 2008.

3. Xavier RJ and Podolsky DK: Unravelling the pathogenesis of inflammatory bowel disease. Nature 448: 427-434, 2007.

4. Medzhitov R, Preston-Hurlburt P and Janeway CA Jr: A human homologue of the Drosophila Toll protein signals activation of adaptive immunity. Nature 388: 394-397, 1997.

5. Ortega-Cava CF, Ishihara S, Rumi MA, et al: Strategic compartmentalization of Toll-like receptor 4 in the mouse gut. J Immunol 170: 3977-3985, 2003.
6. Uematsu S and Akira S: Immune responses of TLR5(+) lamina propira dendritic cells in enterobacterial infection. J Gastroenterol 44: 803-811, 2009.

7. Ishihara S, Rumi MA, Kadowaki Y, et al: Essential role of MD-2 in TLR4-dependent signaling during Helicobacter pyloriassociated gastritis. J Immunol 173: 1406-416, 2004

8. Vijay-Kumar M, Sanders CJ, Taylor RT, et al: Deletion of TLR5 results in spontaneous colitis in mice. J Clin Invest 117: 3909-3921, 2007.

9. Cario E: Therapeutic impact of toll-like receptors on inflammatory bowel diseases: a multiple-edged sword. Inflamm Bowel Dis 14: 411-421, 2008.

10. Gribar SC, Anand RJ, Sodhi CP and Hackam DJ: The role of epithelial Toll-like receptor signaling in the pathogenesis of intestinal inflammation. J Leukoc Biol 83: 493-498, 2008.

11. Okamoto R, Tsuchiya K, Nemoto Y, Akiyama J, Nakamura T, Kanai $\mathrm{T}$ and Watanabe $\mathrm{M}$ : Requirement of Notch activation during regeneration of the intestinal epithelia. Am J Physiol Gastrointest Liver Physiol 296: G23-G35, 2009.

12. Kuhnert F, Davis CR, Wang HT, et al: Essential requirement for Wnt signaling in proliferation of adult small intestine and colon revealed by adenoviral expression of Dickkopf-1. Proc Natl Acad Sci USA 101: 266-271, 2004.

13. Lees CW,Zacharias WJ, Tremelling M, et al: Analysis of germline GLI1 variation implicates hedgehog signalling in the regulation of intestinal inflammatory pathways. PLoS Med 5: e239, 2008.

14. Artavanis-Tsakonas S, Matsuno K and Fortini ME: Notch signaling. Science 268: 225-232, 1995.

15. Artavanis-Tsakonas S, Rand MD and Lake RJ: Notch signaling: cell fate control and signal integration in development. Science 284: 770-776, 1999.

16. Krebs LT, Xue Y, Norton CR, et al: Notch signaling is essential for vascular morphogenesis in mice. Genes Dev 14: 1343-1352, 2000.

17. Fung E, Tang SM, Canner JP, et al: Delta-like 4 induces notch signaling in macrophages: implications for inflammation. Circulation 115: 2948-2956, 2007.

18. Bedogni B, Warneke JA, Nickoloff BJ, et al: Notch1 is an effector of Akt and hypoxia in melanoma development. J Clin Invest 118: 3660-3670, 2008.

19. Schroder N and Gossler A: Expression of Notch pathway components in fetal and adult mouse small intestine. Gene Expr Patterns 2: 247-250, 2002.

20. Katoh $\mathrm{M}$ and Katoh $\mathrm{M}$ : Notch signaling in gastrointestinal tract (Review). Int J Oncol 30: 247-251, 2007.

21. Nakamura T, Tsuchiya K and Watanabe M: Crosstalk between Wnt and Notch signaling in intestinal epithelial cell fate decision. J Gastroenterol 42: 705-710, 2007.

22. Ishizuya-Oka A and Hasebe T: Sonic hedgehog and bone morphogenetic protein-4 signaling pathway involved in epithelial cell renewal along the radial axis of the intestine. Digestion 77: 42-47, 2008.

23. Jiang H, Patel PH, Kohlmaier A, Grenley MO, McEwen DG and Edgar BA: Cytokine/Jak/Stat signaling mediates regeneration and homeostasis in the Drosophila midgut. Cell 137: 1343-1355, 2009.

24. Fre S, Pallavi SK, Huyghe M, et al: Notch and Wnt signals cooperatively control cell proliferation and tumorigenesis in the intestine. Proc Natl Acad Sci USA 106: 6309-6314, 2009.

25. Oshima N, Ishihara S, Rumi MA, et al: A20 is an early responding negative regulator of Toll-like receptor 5 signalling in intestinal epithelial cells during inflammation. Clin Exp Immunol 159: 185-198, 2010.

26. Rhee SH, Im E, Riegler M, Kokkotou E, O'Brien M and Pothoulakis C: Pathophysiological role of Toll-like receptor 5 engagement by bacterial flagellin in colonic inflammation. Proc Natl Acad Sci USA 102: 13610-13615, 2005.

27. Aziz MM, Ishihara S, Rumi MA, et al: Prolactin induces MFG-E8 production in macrophages via transcription factor C/EBPbeta-dependent pathway. Apoptosis 13: 609-620, 2008.

28. Gewirtz AT, Navas TA, Lyons S, Godowski PJ and Madara JL: Cutting edge: bacterial flagellin activates basolaterally expressed TLR5 to induce epithelial proinflammatory gene expression. J Immunol 167: 1882-1885, 2001.

29. Solt LA and May MJ: The IkappaB kinase complex: master regulator of NF-kappaB signaling. Immunol Res 42: 3-18, 2008.

30. Verma UN, Yamamoto Y, Prajapati S and Gaynor RB: Nuclear role of I kappa B Kinase-gamma/NF-kappa B essential modulator (IKK gamma/NEMO) in NF-kappa B-dependent gene expression. J Biol Chem 279: 3509-3515, 2004. 
31. Rudolph D, Yeh WC, Wakeham B, et al: Severe liver degeneration and lack of NF-kappaB activation in NEMO/IKKgammadeficient mice. Genes Dev 14: 854-862, 2000.

32. Shifera AS, Friedman JM and Horwitz MS: IKK gamma (NEMO) is involved in the coordination of the AP-1 and NF-kappa B pathways. Mol Cell Biochem 310: 181-190, 2008.

33. Vales LD and Friedl EM: Binding of C/EBP and RBP (CBF1) to overlapping sites regulates interleukin- 6 gene expression. J Biol Chem 277: 42438-42446, 2002.

34. Moriyama I, Ishihara S, Rumi MA, et al: Decoy oligodeoxynucleotide targeting activator protein-1 (AP-1) attenuates intestinal inflammation in murine experimental colitis. Lab Invest 88 652-663, 2008.

35. Aziz MM, Ishihara S, Mishima Y, et al: MFG-E8 attenuates intestinal inflammation in murine experimental colitis by modulating osteopontin-dependent alphavbeta3 integrin signaling. J Immunol 182: 7222-7232, 2009.

36. van Es JH and Clevers $\mathrm{H}$ : Notch and Wnt inhibitors as potential new drugs for intestinal neoplastic disease. Trends Mol Med 11: 496-502, 2005.

37. Radtke F, Schweisguth F and Pear W: The Notch 'gospel'. EMBO Rep 6: 1120-1125, 2005.
38. Hurlbut GD, Kankel MW, Lake RJ and Artavanis-Tsakonas S: Crossing paths with Notch in the hyper-network. Curr Opin Cell Biol 19: 166-175, 2007.

39. Palaga T, Buranaruk C, Rengpipat S, Fauq AH, Golde TE, Kaufmann SH and Osborne BA: Notch signaling is activated by TLR stimulation and regulates macrophage functions. Eur J Immunol 38: 174-183, 2008.

40. Shin HM, Minter LM, Cho $\mathrm{OH}$, et al: Notch1 augments NF-kappaB activity by facilitating its nuclear retention. EMBO J 25: 129-138, 2006.

41. Osipo C, Golde TE, Osborne BA and Miele LA: Off the beaten pathway: the complex cross talk between Notch and NF-kappaB. Lab Invest 88: 11-17, 2008.

42. Cheng P,Zlobin A, Volgina V, et al: Notch-1 regulates NF-kappaB activity in hemopoietic progenitor cells. J Immunol 167: 4458-4467, 2001.

43. Amsen D, Antov A and Flavell RA: The different faces of Notch in T-helper-cell differentiation. Nat Rev Immunol 9: 116-124, 2009.

44. Abreu MT, Fukata M and Arditi M: TLR signaling in the gut in health and disease. J Immunol 174: 4453-4460, 2005. 